\title{
Common Childhood Masturbation, But Different Sexual Attitudes in Three Male-at-Birth Adolescents: Possible Implications for Sexual Development
}

\author{
Binggen Zhu1,2*, Zheng Li'2, Kayama Jo² \\ ${ }^{1}$ Pudong New Area Mental Health Center, Tongji University School of Medicine, Shanghai, China \\ ${ }^{2}$ Department of Psychiatry, Tenth Peoples' Hospital, Tongji University School of Medicine, Shanghai, China \\ Email: ^binggen.zhu@tongji.edu.cn
}

How to cite this paper: Zhu, B.G., Li, Z. and Jo, K. (2020) Common Childhood Masturbation, But Different Sexual Attitudes in Three Male-at-Birth Adolescents: Possible Implications for Sexual Development. Open Journal of Medical Psychology, 9, 160-167.

https://doi.org/10.4236/ojmp.2020.94013

Received: August 24, 2020

Accepted: September 26, 2020

Published: September 29, 2020

Copyright $\odot 2020$ by author(s) and Scientific Research Publishing Inc. This work is licensed under the Creative Commons Attribution International License (CC BY 4.0).

http://creativecommons.org/licenses/by/4.0/

\begin{abstract}
Although the child masturbation is recognized as not uncommon behavior, our understanding of normative sexual development in humans is fairly limited. To investigate the possible relationship between early childhood masturbation and subsequent sexual cognition, we retrospectively researched three adolescents who had been reared male and who masturbated in early childhood in similar ways, but had different subsequent sexual cognition. The three young people all recalled primary sexual pleasure from masturbation at age 4 or 5 . Their distinctive sexual attitudes could be discerned at age 15 to 20. One was transgender, one was homosexual, and one was heterosexual. Combining recent findings of the neural mechanisms of sexual pleasure and cognition, it can be inferred that the early sexual pleasure in preschoolers might have little significance for the development of sexual cognition in adolescence.
\end{abstract}

\section{Keywords}

Childhood Masturbation, Sexual Attitude, Sexual Cognition, Sexual

Development, Adolescents

\section{Introduction}

Studies of psychosexual development and careful clinical observations have shown that preadolescent children have not been regarded as asexual, and preschool children showing sexual behaviors are not uncommon [1] [2] [3]. Infants 
start to explore things around them, as well as their own body. Happening to discover certain pleasurable areas can lead to self-stimulation again and again. Masturbation is considered as part of a normal spectrum of sexual behaviors in substantial proportions of children and may be observed at any age in childhood [1] [2] [4]. In contrast to traditional concerns or worries about child masturbation, several researchers recently found that early sexual experience with spontaneous masturbation in childhood increased adult sexual interest and possibly had a negative relationship with the hypoactive sexual desire [5] [6]. Although child masturbation is recognized academically, our understanding of normative sexual development in childhood is fairly limited [1] [2] [3] [7]. So far, we do not know if the early masturbation in preadolescents affects the formation of sexual cognition in adolescents, and there are no studies on the underlying neural mechanisms for sexual development and related behaviors, including child masturbation and the origin of sexual awareness or cognition.

We previously presumed that the neural bases for the gratification induced by self-stimulation of the genitalia in younger children (especially in infants, toddlers, and preschoolers) were relevant to the hedonic brain circuits for pleasant sweet tastes, which are independent of the superior brain structures responsible for cognition [7]. In this paper, to investigate the possible relationship between early childhood masturbation and subsequent sexual cognition, we reported three adolescents who had masturbation pleasure at the early age 4 or 5 , and had different sexual attitudes at age 15 - 20. These cases indicated the complexity of subsequent sexual cognition development, although the basic mechanism for the early sexual pleasure in these three men might be unitary.

\section{Case Presentation}

Case $1 \mathrm{~W}$ was 15 years old at the time of the study, and a student in the first-year class of a high school. This participant has since come to identify as a trans girl and so is called "she" here. The participant recalled deliberate rubbing of the penis against the bed since the age of five years old because it was pleasant, usually at home before falling asleep. At age 12 the participant experienced an ejaculation after such rubbing. Moreover, since beginning kindergarten at age four, Case 1 preferred dressing like a girl and liked to play with girls, although still identifying as a boy. Three years before this work, Case 1 not only dressed as a girl at home but also disliked his masculine characteristics. Case 1 came to identify as transgender after reading about it online. One and a half years ago, she fell in love with a male classmate but was rejected and ridiculed by the male classmate. There is nothing about Case 1's body that does not appear male in a standard physical examination. The results of sex hormones testing (including testosterone, estradiol, progesterone, luteinizing hormone, follicle-stimulating hormone, and prolactin) and magnetic resonance imaging (MRI) scans of the brain were consistent with male teenagers in this age cohort. Case 1 was diagnosed as gender identity disorder, the DSM-IV being in use at the time. After a 
series of interviews and discussions with doctors and parents, Case 1 agreed to a compromise by concentrating on her studies first and deferring such treatments as endocrine therapy and plastic surgery until she was older. After two years, she continues to identify as a trans girl.

Case $2 \mathrm{C}$ was at 20 years old, a junior student in a university. He crossed his legs to obtain sexual pleasure since he was four years old. At around 11 years old, he experienced ejaculation after crossing his legs. He favored handsome men and had sexual fantasies about these men since the age of ten. He clearly realized that he was a gay man at 18 years old. After one and a half years of college, he was secretly attracted to several male classmates, but none of them responded positively to him. He sought medical advice because he was depressed for half a year. His physical examination was normal. Two years after this, he still had homosexual interests.

Case $3 \mathrm{P}$ was 18 years old, a university freshman. In the initial consultation, he disclosed that he could not concentrate on his studies, worried about his academic performances, and was not happy for almost two months. Meanwhile, he could not sleep well and lost his appetite. His physical examination was normal. His diagnosis was a major depressive disorder. He received antidepressants (sertraline, escitalopram, and duloxetine, successively) for nine months after seeking two different psychiatrists' advice. His core depressive symptoms were under control, but he still worried about his future and had ruminations that interfered with learning. Therefore, he visited our consulting room for further treatment. He was encouraged to recall his early life. At five years old, he accidentally witnessed his parents having sexual intercourse, and since then he has had a habit of masturbation. His older sister (by more than 7 years) and teachers in nursery school found that he moved his buttocks and rubbed his penis against the bed for sexual pleasure. They tried to stop him several times, and later he did it secretly. About four years ago, he felt guilty about masturbation, as he thought of masturbation as evil and not good for one's health, according to the Chinese traditional theory of shenkui (namely, a loss of virility and energy) [8]. He tried his best to stop masturbating, particularly after having a girlfriend (one and half a year ago), but he failed again and again. We proposed that his residual depressive symptoms originated from his misunderstanding about masturbation and deep feeling of guilt [6]. He continued to take duloxetine, meanwhile, we worked with him on making cognitive modifications over the next three visits. After six weeks, he told us that he has accepted his past and felt that life was good and did not worry and ponder aimlessly now.

\section{Discussion}

1) The peculiarity and possible underlying mechanisms of early masturbation

Masturbation is defined as self-stimulation of the genitalia to get sexual pleasure often to the point of orgasm. Particularly, masturbation in 2 - 5-year-old is much more likely in compliance with a simple self-pleasure principle, with little 
interest in the opposite sex or other individuals [2] [3]. Since it is not triggered by the presence of a sexual partner or erotic visual stimuli, masturbation of 2 5 -year-old involves a rather pure genital touch reward. Provided that children have a complete spinal cord signal transmission pathway dealing with stimulation toward the genitals, the erection and ejaculation are simply organized as spinal reflexes, which lay firm foundations to obtain further genital sexual pleasure [9].

The sexual pleasure cycle for adults, which is similar to the basic structure of pleasure cycles related to other rewards (such as food), can be expressed in terms of motivation-consummation-satiety or wanting-liking-inhibition [9] [10]. However, accompanying or just before masturbation of 2 - 5-year-old, there is almost no sexual desire or "wanting" which can be felt or seen clearly in adolescents and adults. It is more possible that the direct genital stimuli strike the consummatory or liking response and produce gratification without thoughtful "wanting". Therefore, spinal reflexes, the spinal sensory transmission pathway, and the sexual consummation network in the brain might underlie the sexual pleasure experienced in childhood masturbation.

The sexual consummation network and brain mechanisms involved in sexual pleasure that might be overlapped with those related to pleasure from foods ensure that individuals and species seek the elementary rewards allowing survival and procreation [11]. The brain fMRIs of adult men revealed involvement of the lateral hypothalamus, ventral pallidum, middle cingulate cortex, anterior insula (for genital sensory processing), frontal operculum (the secondary somatosensory cortex), inferior parietal lobule (the primary somatosensory cortex), and occipitotemporal cortex in both penile tumescence and sexual penis stimulation [9]. The reward circuitry in the brain is a distributed network [12]. Its central core is located in subcortical regions, including the ventral striatum and midbrain area [13]. Particularly, the ventral pallidum, known to mediate food-liking in rats, signals the onset of penis stimulation and shows decreased activity in the absence of penis stimulation, possibly reflecting inhibitory processes [9]. These subcortical structures form in the second trimester [14], and likely begin working in the late third trimester. Therefore, the clinical reports about infantile masturbation and even fetal masturbation in utero observed by sonography [2] are not impossible situations. Our three cases, $\mathrm{W}, \mathrm{C}$, and $\mathrm{P}$ recalled their primary sexual pleasure from masturbation when $4-5$ years old. The neural mechanisms for their early masturbation pleasures should be basically the same as those mentioned above.

2) The possible underlying brain mechanisms for the mature sexual cognition

Preschoolers have very limited sexual cognition (knowledge and attitude about sex) [2] [3] [15], but masturbation in youths and adults, besides the pleasure via self-stimulation of the genitalia, involve "a complex of feelings, attitudes and fantasies" [16]. This complex is set up gradually by social learning, self-concept development, sexual imagination, personal sexual preferences, etc. 
Although the three young participants in our study experienced similar childhood masturbation pleasure, the developmental processes of their cognition for sex were different. Why did these three young people have different developmental processes for the cognition of sexual identity/orientation? So far, there are no clear scientific findings to answer this question. However, it is known that the brain structures for sexual pleasure and related cognitions create a complicated system involving multiple brain areas [10] [17]. Neuroimaging and animal studies indicate that at least part of a core neural circuit for sexual identity/orientation is related to the subcortical nuclei, such as the bed nucleus of the stria terminalis and anterior and preoptic areas of the hypothalamus [18] [19]. These areas are sexually dimorphic in humans and animals, and formed in a brain developmental process, particularly, occurring during a restricted critical window which is operationally defined by the onset of androgen production by the fetal testis of males [20]. In addition to androgen, recently, many evidences indicated a central role for inflammatory signaling molecules and immune cells in masculinization of brain [20].

Moreover, sexual awareness is associated with cerebral networks involved in self-perception. The key networks are composed of the prefrontal cortex (PFC) and anterior cingulate cortex (ACC), which exert top-down influences on the subcortical regions [10] [21]. In contrast to the ventral striatum and ventral tegmental area, the PFC and ACC mature very late, usually after adolescence [12] [22]. Other than following the trajectory determined by genes and other biological factors, the development of the cognitive regulatory system of the brain is, to a certain extent, influenced by socio-psychological factors, especially during adolescence [21] [23] [24].

3) The two phases hypothesis for the sex development

It can be inferred, from what was described above, that there are two phases during the developmental procedure of sexual behaviors. The primary phase in preschoolers is merely sexual pleasure, the equivalent of consummation or liking in the adult sexual pleasure cycle. Consummatory sexual pleasure can be attained by masturbation in early childhood with little wanting. The first phase is oversimplified, and involves the primary reward neural areas (including the somatosensory cortex, several subcortical regions, spinal cord, etc.). These neural structures mature early and can be in an extraordinary active state in some preschoolers. Another phase arises during adolescence, accompanying the origin of sexual awareness or cognition. A lot of children without a history of masturbation or without experience of sexual pleasure might directly enter this phase. This second phase is complicated and is involved in both subcortical nuclei and the superior brain cortex (the PFC and ACC etc.). The PFC and ACC develop continuously after birth and reach maturity during puberty or later. It is likely that the former phase of sex development cannot substantially guide the formation of the latter phase, namely that the early sexual pleasure in preschoolers might have little significance for the development of sexual cognition in adoles- 
cence. In contrast, the first phase may be manipulated by the second phase with subsequent development. However, the exact relationship between these two phases may not be so simple, and this is worth further study and exploration.

There are some limitations to our present research. First, it is a retrospective case analysis. Integrating case analyses with well-designed prospective research and collecting many more samples should be considered in the future investigations to provide more adequate and accurate data. Moreover, for the elucidation of exact neural mechanisms, functional brain imaging and/or advanced electroencephalography recording should be appropriately applied.

Combining recent findings of the neural mechanisms of sexual pleasure and cognition, we conjectured a roughly two-phase sexual development composed of a primary unitary sexual pleasure and a subsequent multifarious sexual cognition (plus sexual pleasure), and the early sexual pleasure in preschoolers might have little significance for the development of sexual cognition in adolescence.

\section{Ethics Approval and Consent to Participate}

Ethical approval was obtained from the Ethics Committee at the Pudong New Area Mental Health Center, Tongji University School of Medicine. Written informed consent was obtained from all subjects in accordance with the Declaration of Helsinki.

\section{Authors' Contributions}

BZ conceived the study and wrote the manuscript. ZL and KJ helped BZ with recording and following cases.

\section{Funding}

This study was supported by the key discipline construction project of the Health and Family Planning Commission of Pudong New Area, Shanghai, China (PWZzk2017-20).

\section{Conflicts of Interest}

The authors declare no conflicts of interest regarding the publication of this paper.

\section{References}

[1] Elkovitch, N., Latzman, R.D., Hansen, D.J. and Flood, M.F. (2009) Understanding Child Sexual Behavior Problems: A developmental Psychopathology Framework Clinical Psychology Review, 29, 586-598. https://doi.org/10.1016/j.cpr.2009.06.006

[2] Mallants, C. and Casteels, K. (2008) Practical Approach to childhood Masturbation-A Review. European Journal of Pediatrics, 167, 1111-1117. https://doi.org/10.1007/s00431-008-0766-2

[3] Wurtele, S.K. and Kenny, M.C. (2011) Normative Sexuality Development in Childhood: Implications for Developmental Guidance and Prevention of Childhood Sexual Abuse. Journal of Multicultural Counseling and Development, 43, 1-24. 
[4] Janssen, D.K. (2007) First Stirrings: Cultural Notes on Orgasm, Ejaculation, and Wet Dreams. The Journal of Sex Research, 44, 122-134. https://doi.org/10.1080/00224490701263595

[5] Griffee, K., O’Keefe, S.L., Beard, K.W., Young, D.H., Kommor, M.J. and Linz, T.D. (2014) Human Sexual Development Is Subject to Critical Period Learning: Paradigm-Shifting Implications for Sexual Therapy and for Child-Rearing. International Journal of Sexual Health, 26, 295-313. https://doi.org/10.1080/19317611.2014.898725

[6] Schuke, E. (2014) Female Childhood Orgasms: Findings from Adult Analysis. Studies in Gender and Sexuality, 15, 3-19. https://doi.org/10.1080/15240657.2014.877723

[7] Zhu, B.G., Kong, H.J., Sun, Z.Q. and Zhu, R.S. (2011) Transition from Paroxysmal Disorder in Infancy to the Masturbatory Orgasm in Childhood. International Journal of Sexual Health, 23, 278-281. https://doi.org/10.1080/19317611.2011.621821

[8] Das, A., Parish, W.L. and Laumann, E.O. (2009) Masturbation in Urban China. Archives of Sexual Behavior, 38, 108-120.

https://doi.org/10.1007/s10508-007-9222-Z

[9] Georgiadis, J.R., Kringelbach, M.L. and Pfaus, J.P. (2012) Sex for Fun: A Synthesis of Human and Animal Neurobiology. Nature Reviews Urology, 9, 486-498. https://doi.org/10.1038/nrurol.2012.151

[10] Georgiadis, J.R. and Kringelbach, M.L. (2012) The Human Sexual Response Cycle: Brain Imaging Evidence Linking Sex to Other Pleasures. Progress in Neurobiology, 98, 49-81. https://doi.org/10.1016/j.pneurobio.2012.05.004

[11] Kringelbach, M.L., Stein, A. and Van Hartevelt, T.J. (2012) The Functional Human Neuroanatomy of Food Pleasure Cycles. Physiology \& Behavior, 106, 307-316. https://doi.org/10.1016/j.physbeh.2012.03.023

[12] Sescousse, G., Caldú, X., Segura, B. and Dreher, J. (2013) Processing of Primary and Secondary Rewards: A Quantitative Meta-Analysis and Review of Human Functional Neuroimaging Studies. Neuroscience and Biobehavioral Reviews, 37, 681-696. https://doi.org/10.1016/j.neubiorev.2013.02.002

[13] Richards, J.M., Plate, R.C. and Ernst, M. (2013) A Systematic Review of fMRI Reward Paradigms Used in Studies of Adolescents vs. Adults: the Impact of Task Design and Implications for Understanding Neurodevelopment. Neuroscience and Biobehavioral Reviews, 37, 976-991. https://doi.org/10.1016/j.neubiorev.2013.02.002

[14] Meng, H.W., Zhang, Z.H., Geng, H.Q., Lin, X.T., Feng, L., Teng, G.J., Fang, F., Zang, F.C. and Liu, S.W. (2012) Development of the Subcortical Brain Structures in the Second Trimester: Assessment with 7.0-T MRI. Neuroradiology, 54, 1153-1159. https://doi.org/10.1007/s00234-012-1069-x

[15] Martin, C.L. and Ruble, D.N. (2009) Patterns of Gender Development. Annual Review of Psychology, 61, 353-381.

https://doi.org/10.1146/annurev.psych.093008.100511

[16] Phillips, D.F. and Seshia, S.S. (2013) Gratification, Masturbation or Paroxysmal Hyperkinetic Motor Syndrome of Infancy? Canadian Journal of Neurological Sciences, 40, 278-279. https://doi.org/10.1017/S0317167100014189

[17] Ruesink, G.B. and Georgiadis, J.R. (2017) Brain Imaging of Human Sexual Response: Recent Developments and Future Directions. Current Sexual Health Reports, 9,183-191. https://doi.org/10.1007/s11930-017-0123-4

[18] Lenz, K.M., Pickett, L.A., Wright, C.L., Davis, K.T., Galan, A. and Mccarthy, M.M. (2018) Mast Cells in the Developing Brain Determine Adult Sexual Behavior. Jour- 
nal of Neuroscience, 38, 8044-8059.

https://doi.org/10.1523/JNEUROSCI.1176-18.2018

[19] Roselli, C.E. (2018) Neurobiology of Gender Identity and Sexual Orientation. Journal of Neuroendocrinology, 30, e12562. https://doi.org/10.1111/jne.12562

[20] Mccarthy, M.M. (2020) A New View of Sexual Differentiation of Mammalian Brain. Journal of Comparative Physiology A, 206, 369-378. https://doi.org/10.1007/s00359-019-01376-8

[21] Larsen, B. and Luna, B. (2018) Adolescence as a Neurobiological Critical Period for the Development of Higher-Order Cognition. Neuroscience and Biobehavioral Reviews, 94,179-195. https://doi.org/10.1016/j.neubiorev.2018.09.005

[22] Herting, M.M. and Sowell, E.R. (2017) Puberty and Structural Brain Development in Humans. Frontiers in Neuroendocrinology, 44, 122-137. https://doi.org/10.1016/j.yfrne.2016.12.003

[23] Petanjek, Z., Judas, M.S., Rasin, M.R., Uylings, H.B., Rakic, P. and Kostovic, I. (2011) Extraordinary Neoteny of Synaptic Spines in the Human Prefrontal Cortex. Proceedings of the National Academy of Sciences of the United States of America, 108, 13281-13286. https://doi.org/10.1073/pnas.1105108108

[24] Pfaus, J.G., Kippin T.E., Coria-Avila, G.A., Gelez, H., Afonso, V.M., Ismail, N. and Parada, M. (2012) Who, What, Where, When (and Maybe Even Why)? How the Experience of Sexual Reward Connects Sexual Desire, Preference, and Performance. Archives of Sexual Behavior, 41, 31-62. https://doi.org/10.1007/s10508-012-9935-5 